\title{
EL CONCEPTO DE CLÁUSULA EN EDUARDO BENOT
}

\author{
Juan M. Lope Blanch \\ Universidad Nacional Autónoma \\ El Colegio de México
}

\begin{abstract}
Hace ya muchos años, Amado Alonso consideraba que era necesario desterrar de las gramáticas de la lengua española el término cláusula por juzgarlo neologismo innecesario y confuso: "En algunas gramáticas extranjeras las expresiones que son oraciones por la forma pero no por el sentido se llaman miembros de oración con forma de oración, lo cual en español sería buena explicación pero no un nombre; en las nuestras se suelen llamar, desde Bello, proposiciones para distinguirlas, convencionalmente, de las oraciones plenas. Oración es el término tradicional en nuestras gramáticas para designar la expresión de sentido completo. Por desgracia, algunos gramáticos recientes han introducido otro término, también convencional, cláusula, con el cual designan especialmente a la oración de sentido completo, como si el tener sentido completo fuese cosa de una clase especial de oraciones y no lo normal. Es evidente que, sin embargo, conviene dar el nombre especial a las oraciones especiales, y conservar el nombre tradicional de oración para las oraciones normales. Las oraciones especiales son las que, si bien tienen sujeto y predicado, no tienen sentido completo, y el nombre especial debe reservarse para ellas, como hizo Bello. Muy de desear es que se destierre de nuestras gramáticas el término cláusula, que es impropio, injustificado y provocador de confusiones" 1.
\end{abstract}

Hace ya también algunos años hice ver cuán equivocados eran esos juicios, por cuanto que el término cláusula se ha usado en la gramática espa-

1 Amado Alonso y Pedro Henriquez Urefia, Gramática castellana: Segundo curso. Cito por la 11.a edición, Buenos Aires, 1953, § 19, pág. 23. 
ñola desde el momento mismo de su nacimiento por obra de Nebrija, y fue empleado por los grandes lingüistas españoles del Siglo de Oro y por sus continuadores de las centurias siguientes hasta llegar a nuestro siglo ${ }^{2}$. En esa misma ocasión dije también, como de pasada, que Eduardo Benot, siguiendo a Julio Cejador, habia coincidido con los gramáticos áureos en su concepción de la cláusula como la unidad de comunicación de sentido completo, ya que la definía como "toda combinación de combinaciones con sentido cabal e independiente" ${ }^{3}$. Cometi entonces el error de pensar que Benot habia dicho tal cosa "en seguimiento" de Cejador, como si el gramático andaluz se hubiera inspirado en las doctrinas lingüisticas del aragonés, siendo aquél anterior a éste. El error, en que han incurrido diversos historiadores de la gramática española 4, obedece al hecho de considerar, equivocadamente, que las ideas de Benot fueron expresadas en su obra gramatical más conocida, el Arte de hablar, publicada en 1910, tres años después de la muerte de su autor, es decir, un lustro después de que Cejador hubiera publicado su estudio sobre la Lengua de Cervantes - Madrid, 1905-, cuando lo cierto es que Benot habia puesto los fundamentos firmes de todo su edificio gramatical en una obra muy anterior, los Breves apuntes sobre los casos y las oraciones, publicada en Cádiz posiblemente en 1852.

Mucho más recientemente, la profesora Martínez Linares considera que lo hecho por Benot en relación con los conceptos de cláusula y oración no fue simplemente retomar la tradición española relativa a esos conceptos, ni cree tampoco que el gramático gaditano se sirva "de una terminologia diferente para denotar una distinción equiparable a la que estableció Bello entre proposición y oración" "5. Lo primero me mueve a escribir estas páginas, para tratar de precisar los conceptos que Benot denominó cláusula y oración, asi como tesis y anéutesis; lo segundo me inclina a hacer una rectificación necesaria en aras de la precisión histórica. Comencemos por esto último.

Ya es creencia generalizada —en que coincide Martínez Linares y en que coincidieron, según vimos en páginas anteriores, Amado Alonso y Henríquez Ureña - que a Bello pertenece la fundamental distinción entre los conceptos de oración y de proposición, en cuanto unidad de manifestación con sentido completo el primero, y unidad formal carente de tal autonomía

2 Cf. mi artículo sobre "El concepto de cláusula", Boletin de la Academia Puertorriqueña de la Lengua Española, V, 1977, págs. 83-91.

3 Cf. artículo citado en la nota anterior, pág. 90. -Reiteré mi observación en el artículo sobre "La cláusula y el análisis del discurso", en la NRFH, XXVIII, 1979, págs. 1-29. (Cf., en especial, págs. 8-9).

- Cf. mi artículo sobre "Eduardo Benot y la clasificación de las oraciones", que se publicará en el número 1 de la revista Romanistik in Geschichte und Gegenwart.

s María A. Martínez Linares, "La oración compuesta por subordinación en la gramática de Eduardo Benot", Estudios de Lingüistica, Universidad de Alicante, 5, 1988-1989, págs. 191-199. (V. pág. 193). 
semántica el segundo. Sus definiciones fueron muy claras y precisas: "El sujeto y el atributo unidos forman la proposición", pero "Se llama oración toda proposición o conjunto de proposiciones que forman sentido completo: de que está alfombrada la ribera es proposición perfecta, pero no es oración" ".

Pues bien, creo haber mostrado hace algún tiempo que tal distinción había sido ya hecha, siglos antes, por los gramáticos españoles del Siglo de Oro $^{7}$. Y con nomenclatura, en mi opinión, más precisa y justificable que la del gran venezolano. Implícita tal distinción ya en Nebrija ${ }^{8}$, fue formulada de manera nítida y rigurosa por Cristóbal Villalón, a quien corresponde la siguiente explicación, que envidiarían muchos gramáticos de nuestro siglo: "deue notar, que ay differençia entre clausula y oraçion. Que oraçion, a lo menos perfecta, se compone por la mayor parte de persona que haze alguna obra: y de verbo: y de persona en quien se denota passar, o hazer aquella obra el verbo... Y digo, que clausula es a la vezes vna oraçion sola: y otras vezes es vn ayuntamiento de muchas oraçiones: las quales todas juntas espresan y manifiestan cumplidamente el conçibimiento del hombre en el proposito que tiene tomado para hablar" 9 .

La distinción permanece firme y clara en el Arte de Gonzalo Correas: "En la Gramatica se llama orazion la rrazon breve i sentido o sentenzia que se haze con nonbre $i$ verbo conzertados con numero $i$ persona, que son las partes esenziales de la orazion gramatical... con las oraziones gramaticales multiplicandose unas tras otras, $i$ muchas vezes mezclandose unas entre otras se haze el periodo, ó corto con pocas oraziones, i á vezes con solo una, ó largo con muchas. Periodo es palavra Griega... i es lo mesmo que en Latin, i Rromanze clausula" ${ }^{10}$. Los mismos conceptos en el Tesoro de la lengua castellana o española (1611) de Sebastián de Covarrubias, en el Epitome de la ortografía latina y castellana (1614) de Bartolomé Jiménez Patón, y en otras obras de diversos autores de nuestra firme tradición gramatical.

- Andrés Bello, Gramática de la lengua castellana, Santiago, 1847. (Cito por la edición de las Obras completas hecha por el Ministerio de Educación, vol. IV, Caracas, 1951. Cf. $\$ \S 35$ y 308 respectivamente).

7 Cf. mi ponencia sobre "Bello y el concepto de oración", en Bello y Chile: Actas del Tercer Congreso del Bicentenario, Caracas, vol. I, 1981, págs. 461-470. (Recogido también en mi libro de Estudios de historia lingüistica hispánica, Madrid, Arco Libros, 1990, págs. 213-224).

8 Cf. mi ensayo sobre "Los sintagmas extensos en Nebrija", en Estudios nebrisenses (coordinados por Manuel Alvar), Madrid, Instituto de Cooperación Iberoamericana, 1992, págs. 147-158. (Recogido también en mi libro Nebrija cinco siglos después, México, UNAM, 1994).

- Licenciado Villalón, Gramática castellana, Anvers, 1558, pág. 85. (Cito por la edición facsimilar de Constantino García, Madrid, 1971).

10 Arte de la lengua española castellana (1625). Cito por la edición de Emilio Alarcos Garcia, Madrid, 1954, págs. 132 y 135. 
Lo que hizo Bello no fuc, pues, establecer la distinción entre la unidad formal de la gramática - la oración de los clásicos - y la unidad conceptual de comunicación - la cláusula-, sino dar el nombre de proposición a aquélla y el de oración a ésta, interrumpiendo una sólida tradición y trasladando la unidad fundamental de la gramática - esto es, de la morfosintaxis - de su ámbito propio al de la semántica. Confieso que, en esencia, me sitúo más cerca de Villalón que de Bello, según he declarado en otro lugar ${ }^{11}$.

Las unidades sintácticas mayores presentan una distribución original en la obra gramatical de Eduardo Benot, originalidad que se extiende a los propios nombres que el gramático les proporciona. Son ellas las tesis y las anéutesis, de un lado, las oraciones y frases por otro, y las cláusulas por un tercero, amén de otras denominaciones secundarias y menos precisas o importantes desde el punto de vista gramatical, como las enunciaciones y los grupos o entidades elocutivas.

Lleva razón la profesora Martínez Linares: La distinción que Benot observa entre cláusula y oración no es la misma que apreciaba Andrés Bello entre oración y proposición respectivamente y que habia ya establecido - como antes he indicado- el Licenciado Villalón entre cláusula y oración. En realidad, lo que tradicionalmente se había denominado oración en lingüistica española ${ }^{12}$ recibe los nombres de tesis y de anéutesis en las obras de Benot, en tanto que el término cláusula tiene alcances muy distintos en aquéllos y en este último.

Para Villalón - a cuyas ideas me adhiero básicamente ${ }^{13}$ - la cláusula es, como vimos, la oración gramatical o el conjunto de oraciones que manifiestan un pensamiento completo y tienen autonomia formal en el acto de la elocución. Fónicamente es la expresión contenida entre dos pausas totales, entre el comienzo de un enunciado y su pausa final ${ }^{14}$. Como pronto veremos, para Benot la cláusula no es exactamente lo mismo - aunque presente muchos puntos de coincidencia con el concepto que de ella tengo-, ya que, según el gramático gaditano, puede haber dos o más cláusulas dentro de un enunciado incluido entre dos pausas totales.

\footnotetext{
11 Cf. mi libro sobre El concepto de oración en la lingüistica española, México, UNAM, 2. ${ }^{\mathrm{a}}$ ed., 1984.

12 Cf. el libro citado en la nota anterior, en especial págs. 97-99.

13 Cf. mi libro sobre el Análisis gramatical del discurso, México, UNAM, 2.a edición, 1987, págs. 13 y $53-54$

14 De manera que un mismo comunicado puede expresarse a través de una o de varias cláusulas. Así, al decir "No creo nada de lo que dices, porque tú eres muy mentiroso", el pensamiento del hablante —el "conçibimiento" que desea exteriorizar- se ha manifestado a través de una sola cláusula; pero si se dijera "No creo nada de lo que dices. $[$ Punto $=$ pausa final $]$ Porque tú eres muy mentiroso", el mensaje se habría expresado a través de dos cláusulas. $\mathbf{Y}$ en un diálogo como "¿Cuándo lo harás? -Mañana", aparecen dos cláusulas.
} 
De las unidades sintácticas mayores consideradas por Benot, todas - con la sola excepción, tal vez, de la cláusula - quedan bien definidas y delimitadas. Tesis y anéutesis por un lado y oración por otro están claramente diferenciadas. Las dos primeras son expresiones construidas en torno a un verbo conjugado que tienen sentido completo y pueden aparecer en el discurso por si mismas, independientemente. En cambio las oraciones son expresiones que, si bien están construidas en torno a un verbo en forma personal, no tienen sentido completo y no pueden, por ello, aparecer por sí mismas, aisladamente, en el discurso, sino que se adjuntan a alguna tesis o a alguna anéutesis. Entre estas dos últimas existe también una clara diferencia: las tesis son expresiones de carácter afirmativo, en tanto que las anéutesis no tienen tal carácter, sino otros muy diversos, como el interrogativo, el optativo, el imperativo, etc. De manera que "Los perros ladran" o "Voy a su casa" son tesis, mientras que "¿Quién ladra?" o "Ve a su casa" son anéutesis, y los segundos elementos de "Ladra el perro que te mordió" y de "Ve a su casa para que te perdone" son oraciones.

Estas delimitaciones quedan claramente establecidas en el pensamiento gramatical de Benot desde su primera obra de tal carácter, los Breves apuntes, hasta la última, su póstuma Arte de hablar, pasando por la más extensa, la Arquitectura de las lenguas ${ }^{15}$. Pero no siempre sus definiciones son exactamente iguales en la forma, aunque si coinciden en el concepto. Inicialmente, en los Apuntes, decia: "Las cláusulas, tanto de la voz activa como de la voz pasiva, construidas en la forma afirmativa se llaman tesis. Las cláusulas construídas en las otras formas se llaman anéutesis" (pág. 57). Tanto tesis como anéutesis son cláusulas que "Forman SENTIDo PERFECTO POR sí SOLAS. En lo cual difieren de otros conjuntos de palabras que sólo existen de un modo Dependiente dentro de las tesis ó de las anéutesis" (pág. 58). Se refiere páginas después a "las cláusulas de sentido completo (tesis ó anéutesis) y [a] las de SENTIDo incompleto (oraciones)” (pág. 137). En el Arte de hablar, no llama ya cláusulas a esas tres unidades sintácticas, sino combinaciones, lo cual no deja de ser significativo, como después veremos. Dice: "Así, se reservará el nombre de oraciones para toda combinación que no tenga sentido cabal ó independiente; y se dará el nombre de tesis a las combinaciones de sentido independiente cuyo objeto sea AfIRMar; y se denominarán por último anéutesis las combinaciones de sentido independiente, que tengan por objeto expresar los fenómenos psicológicos distintos de la

15 La primera edición -que nunca he logrado ver- de los Breves apuntes sobre los casos y las oraciones debió de aparecer en Cádiz hacia 1852; me he servido de la edición -acaso definitiva- de Madrid, 1888. Del Arte de hablar (Madrid, 1910) hay una reciente reproducción facsímil hecha por Ramón Sarmiento (Barcelona, 1991). De la Arquitectura de las lenguas utilizo la primera edición, en tres volúmenes, de Madrid, 1889. 
afirmación" (pág. 18). Páginas después las llama "entidades elocutivas", pero las define de manera similar ${ }^{16}$.

Aunque podriamos decir que tanto tesis como anéutesis son las hoy llamadas "oraciones principales o independientes", en tanto que lo que Benot llama oraciones son solamente las "subordinadas" - cosa que el mismo gramático apunta-, dada su afición a dar siempre nombres diferentes a conceptos diferentes, rechaza tales denominaciones, y lo justifica debidamente: A las tesis y a las anéutesis, "para diferenciarlas de otros conjuntos de palabras que, aisladas, no ofrecen sentido completo, se las designa también con las denominaciones de ORACIONES PRINCIPALES ú ORACIONES INDEPENDIENTES" (Apuntes, pág. 58), pero en nota al pie hace explícito su rechazo: "Conviene una sola denominación: TESIS; ANÉUTEsis. -Porque, como luego se verá, se llama también oraciones á los conjuntos de palabras que no forman sentido perfecto por si solas". Y, en efecto, en muchos lugares de sus obras define así a lo que él llama oraciones, las cuales "difieren de las tesis y de las anéutesis en que No TIENEN SENTIDO COMPLETO DE POR sí, ni pueden aparecer solas en la locución" (Apuntes, pág. 69; lo mismo en Arte, pág. 88 $\mathrm{y}$ otras muchas). Además las oraciones son elementos DETERMinantes [o sea, complementarios] (Arte, pág. 83), en tanto que las tesis y anéutesis son autónomos o primarios.

Establece también Benot otra clara distinción entre oraciones y frases. Ambas son estructuras determinantes, pero en tanto que las oraciones tienen siempre un verbo en forma personal, el verbo de las frases está en forma no conjugada [es un verboide]: "Al entrar el verano llegará el batallón" es una cláusula en que figura una frase: "Cuando entre el verano llegará el batallón” tiene una oración (Apuntes, pág. 91). La misma doctrina en el Arte ${ }^{17}$. Frases y oraciones son, por otro lado, partes integrantes de la tesis $y$ de las anéutesis, en unión de las cuales forman la cláusula: "con las FRASES y con las ORACIONES ó entidades elocutivas enteras, pero no independientes, se construyen las TESIS y las ANÉUTESIS, que son entidades clocutivas enteras de sentido absoluto gramatical ${ }^{18}$, y nó subordinado" (Apuntes, pág. 126).

\footnotetext{
16 "Las entidades elocutivas con verbo (expreso o suplido) son de dos clases: $1 .^{\text {a }}$ De sentido independiente; se subdividen en tesis y en anéutesis. Las primeras tienen por objeto el afirmar; las segundas tienen por objeto el expresar los demás fenómenos internos distintos de la afirmación... 2. ${ }^{2}$ Por otra parte, existen entidades elocutivas compuestas de varias palabras entre las cuales hay verbo, y que, sin embargo, carecen de sentido independiente... [pero que] son elementos indispensables en la composición de las cláusulas" (págs. 82-83). La misma doctrina en la pág. 88.

17 "Las FrASES-ADVERBio se diferencian de las ORACIONES-ADVERBio en que el verbo de las oraciones aparece siempre en desinencia personal, y el de las frases no. Regularmente, las frases-adverbio se construyen con infinitivos ó con gerundios" (Arte, pág. 259).

18 Excelente me parece esta precisión que hace Benot al referirse al "sentido gra-
} 
Creo, en cambio, que no queda tan nitidamente definido el concepto de cláusula como los de tesis, anéutesis y oración. No coincide aquél plenamente -como antes advertia- con el de Villalón, que yo he abrazado y glosado. Esta totalidad comunicativa o expresión completa en el momento del habla coincide más bien con lo que Benot, sin definir precisamente, denomina unas veces "entidad elocutiva" o "construcción o grupo elocutivo" y otras veces "enunciación"; esto es, el enunciado global, lo dicho. Son todos ellos términos que aparecen muy ocasionalmente en los Apuntes $^{19}$, pero que se repiten con frecuencia en el Arte: Tesis, anéutesis y oraciones son "entidades elocutivas" diferentes (pág. 82) o "grupos elocutivos" (pág. 88) o "construcciones elocutivas" (pág. 46) o "enunciaciones" (pág. 96). Sinónimos todos de lo que yo considero cláusulas o enunciados. Pero acaso para Benot la cláusula sea, en parte, otra cosa. En los Apuntes no proporciona ninguna definición del concepto. Se refiere a él como equivalente de tesis y de anéutesis, y cuando ejemplifica presenta expresiones oracionales independientes de mayor o menor complejidad. Dice, por ejemplo: "Las tesis y las anéutesis suelen denominarse genéricamente "cláusulas"" (pág. 58). O "en una misma cláusula puede haber muchos Ablativos [o complementos circunstanciales]. Juan va por las tardes al campo con su mujer en carretela descubierta" (pág. 19). Las frases y oraciones que complementan a una tesis o anéutesis son también parte integrante de la cláusula: "Al entrar el verano llegará el batallón para guarecer la plaza" (pág. 91) es una sóla cláusula, como lo es también el enunciado "Cuando entre el verano llegará el batallón para que la plaza quede bien guarnecida".

En su obra más extensa, la Arquitectura de las lenguas, proporciona ya una definición precisa de la cláusula: "Llamaré cLÁusula á todo conjunto ó masa de palabras que tiene sentido integro por si. Todas son entidades de sentido perfecto é independiente: Juan comió el pan" (pág. 314). Finalmente en el Arte de hablar ofrece otra definición algo más específica: "El conjunto de palabras que constituyen una combinación de combinaciones, se llama cláusula", cuyo elemento nuclear es el verbo (pág. 47). Su concepto de lo que es una "combinación de combinaciones" queda explicado en el capitulo VI de la sección 7." pág. 89: Se habla a través de "combinaciones de signos, las cuales son de tres clases. La primera se refiere a las "combinaciones de raices y afijos"; las segundas, a combinaciones de palabras para precisar $o$ aumentar el significado de una de ellas [locuciones nominales] ${ }^{20}$; y la

matical", intuyendo tal vez su diferencia esencial respecto del sentido semántico o conceptual.

10 Creo que sólo figura alli el de entidad elocutiva, pero no los otros, aunque no estoy totalmente seguro de ello.

20 "Estos complejos elocutivos dan á conocer los objetos con sus caracteres y pro- 
tercera, "la combinación de las combinaciones que constituyen lo individual, da á conocer por medio de la correspondiente clíusula lo que acerca de esos objetos siente, piensa ó quiere aquel que habla" ${ }^{21}$, de manera que a la cláusula corresponde expresar el propósito comunicativo del hablante: "La vida elocutiva está sólo en la cláusula" (pág. 91) ${ }^{22}$.

I.o hasta aquí dicho parece corresponder al concepto que de la cláusula tenian los gramáticos españoles clásicos, comenzando por Villalón. Pero hallo una diferencia muy importante. Un enunciado completo, expresión comprendida entre dos pausas totales o silencios, puede ser no una sola cláusula, sino dos o más. Un enunciado como "Juan y Pedro van al teatro", que tradicionalmente se consideraria formado por una sola cláusula, incluye, en opinión de Benot, dos cláusulas: "Si decimos Juan y Pedro van al teatro, la conjunción $Y$ une en realidad las dos cláusulas siguientes: Juan va al teatro y Pedro va al teatro" (pág. 93). De manera que el concepto de cláusula parece identificarse con el de tesis o anéutesis, aunque tampoco plenamente. En toda cláusula debe haber siempre una tesis o una anéutesis, y toda tesis o anéutesis son núcleo formativo de cláusula; pero ésta puede incluir, además, frases y oraciones complementarias. Asi, "Al salir el sol, partiremos" sería una sola cláusula constituida por una frase temporal y una tesis; “¿Qué harás cuando llegue tu padre?" es una cláusula formada por una anéutesis y una oración temporal ${ }^{23}$. Pero los enunciados constituidos por dos o más tesis -0 anéutesis - coordinadas entre sí forman dos o más cláusulas. De manera que "Pedro trabaja y María estudia, pero ninguno está contento con esa situación" sería una entidad elocutiva $\longrightarrow$ enunciación - integrada por tres cláusulas, no por una sola. Al menos, tal es la idea que extraigo de lo que Benot escribe.

Asi me lo hace pensar también la distinción que él establece entre nexos y conjunciones. Los primeros serian los pronombres relativos y las que hoy

piedades. Son como en la construcción de los edificios las puertas, las escaleras, los tabiques, los pavimentos" (pág. 89).

21 Y añade: "Estas combinaciones de combinaciones son, como en Arquitectura, el edificio completo que nos guarece de la intemperie y nos permite ejercer nuestros oficios ó profesiones" (o sea, en el caso de la lengua, nos permite hablar). Previamente, en el capítulo I de la sección 3." se había ocupado ya Benot del concepto de "combinaciones" (págs. 44-45).

${ }_{22}$ Estas "combinaciones de combinaciones" por su parte pueden ser de dos tipos: de sentido cabal e independiente - tesis y anéutesis- o sin sentido cabal e independiente -oraciones- (Arte, pág. 18). Sólo las primeras originan una cláusula; las segundas, es decir las oraciones, son sólo parte de la cláusula, cuyo núcleo ha de ser una tesis o una anéutesis.

${ }^{23}$ Así, al hablar de las "oraciones condicionales" (Apuntes, p. 151) señala que "esta clase de oraciones consta de dos miembros: uno con un Verbo condicionante y otro con un Verbo condicionado", y puntualiza en nota al pie: "De los dos miembros que se encuentran en estas cláusulas, el principal es una ANÉuTESIS y el subordinado UN ADVERBIO-ORACIÓN". 
consideramos conjunciones subordinantes; las segundas serían las hoy denominadas conjunciones coordinantes. Explica Benot: "En todos los grupos de palabras entre los cuales existe un verbo, ya en las oraciones-adverbio, ya en las oraciones-adjetivo, hay un vocablo de capital importancia: el que principia la oración... Esta palabra inicial de grupo se llama nexo" (Arte, pág. 86 ; cf. también pág. 199). Y enumera los siguientes: que, cuyo, quien, cual, asi como cuando, antes que, después que, para que, porque. En cambio, "las palabras que enlazan unas cláusulas con otras se llaman conjunciones" (pág. 93). Cláusula en su sentido restringido, no en el de Villalón: "la conjunción une siempre cláusulas constituidas por tesis. Igualmente puede unir cláusulas constituidas por anéutesis: «No enseño á Juan NI á Pedro». «¿ Van Pablo y Pedro á los toros?" "24.

Aunque no emplea sistemáticamente, como hoy se hace, los términos coordinación y subordinación, su concepto parece claro en la mente de Benot. Los nexos introducen los sintagmas que él denomina precisamente oraciones -ya sean de función adjetiva, ya adverbial, ya sustantiva-, esto es oraciones subordinadas, en tanto que las conjunciones enlazan oraciones independientes -tesis o anéutesis - entre si, es decir unidades predicativas en relación coordinante. Su propia clasificación lo prueba: "Por determinar las conjunciones una relación de enlace, se dividen principalmente en copulativas, disyuntivas y adversativas" (Arte, pág. 93), las cuales son $y, e ́, n i, q u e$ - en uso copulativo: "cose que te cose"-, $\delta$, ya, pero, aunque, sino, a pesar $d e$, esto es, conjunciones propiamente coordinantes ${ }^{25}$.

Distingue todavía Benot una tercera clase -0 una subclase dentro de los nexos- que denomina nexos conjuntivos. Son los que preceden a oraciones subordinadas de función sustantiva: "Los substantivos-oración van precedido de nexos especiales que se llaman conjuntrvos... Son: que, si, como, cuando, donde" (Arte, pág. 288). Y añade: "Estos nexos conjuntivos quitan á los substantivos-oración su sentido independiente” (pág. 289). En realidad, lo que varía en el caso de las oraciones sustantivas respecto de las adjetivas y adverbiales no es la clase de sus nexos respectivos - hay mayor afinidad entre los de las oraciones sustantivas y adverbiales que entre los de estas

24 El concepto de nexos verdaderamente interclausulares no figura aún en la obra de Benot, naturalmente. Ni está claro todavía en la gramática de nuestro tiempo. Se trata de nexos como sin embargo, no obstante, empero, por consiguiente, etc., usados como enlace entre dos cláusulas, en construcciones del tipo siguiente: "Estaba muy cansado después de tantas horas de esfuerzo ininterrumpido. Sin embargo siguió trabajando hasta el amanecer", o bien "Habian estado discutiendo el asunto durante horas sin llegar a acuerdo alguno. Por consiguiente decidieron levantar la sesión".

25 En cambio, no lo son las subordinantes: "No son, pues, conjunciones propiamente dichas las llamadas condicionales: Si, como, dado que, etc., ni las llamadas causales: porque, en virtud de, por causa de; ni las finales: Para que, á fin de que", a las cuales corresponde el nombre de nexos (pág. 94). 
últimas y los pronombres relativos de las adjetivas-, sino de la naturaleza de las oraciones mismas. En efecto, los sustantivos-oración coinciden con los sustantivos-adjetivo y con los sustantivos-adverbio en que "no tienen sentido por si propios", frente a lo que sucede en el caso de las tesis y las anéutesis (Apuntaciones, pág. 109), pero se diferencian de los dos últimos en que éstos cumplen funciones determinantes, esto es, complementarias de sustantivos o de verbos respectivamente ${ }^{26}$, en tanto que los sustantivos-oración sustituyen funcionalmente a sustantivos morfológicos; "Son, pues, entidades elocutivas enteras, aunque no independientes, formadas para suplir la falta de sustantivos en la lengua, $y$ no destinadas á determinar, circunscribir, ni modificar" (Arte, pág. 109), como las oraciones adjetivas y las adverbiales ${ }^{27}$.

Volviendo a las cláusulas, cabe señalar que, si bien la cláusula queda formalmente definida por la relación existente entre un sujeto - nominativoy un atributo o predicado -verbo- [cf. Apuntes, pág. 139: “ATributo (ó PREDICADo) es lo que se afirma: sUjeTo de quien se afirma (conste de una ó de muchas palabras)" 28 . V. además Arte, pág. 53], Advierte Benot que existen también algunas cláusulas que carecen del sustantivo sujeto, lo cual ocurre "cuando se trata de ciertos fenómenos naturales: relampaguea, amanece, hiela" (Arte, pág. 51). Por otro lado, "el fin elocutivo de una enunciación puede exteriorizarse sin verbo" (pág. 96), en expresiones como „Hermosa mujer!, ,Valiente bicho!, En casa del herrero, cuchillo de palo o La mujer casada, la pierna quebrada, y en casa.

Según la naturaleza de la expresión, por otra parte, "las cláusulas son susceptibles de varias formas. Las principales son: afirmativa, negativa, interrogativa, negativo-interrogativa (Apuntes, pág. 44), admirativa, optativa, imperativa y condicional (id., pág. 57).

La clasificación que de las oraçiones —esto es, de las subordinadas - hizo Benot ya en sus Breves apuntes, dividiéndolas en sustantivas (oracionessustantivo), adjetivas (oraciones-adjetivo) y adverbiales (oraciones-adverbio) es la más importante y significativa aportación del gramático andaluz al progreso de la lingüistica española; tal clasificación, puntualizada medio siglo

2 El concepto y las clases de elementos determinantes quedan explicados en el capítulo III de la sección $7 .^{\text {a }}$, págs. 83-85 del Arte de hablar.

I7 "Tanto las oraciones-adjetivo como las oraciones-adverbio tienen por objeto determinar ó modificar, y, en todo caso, limitar y restringir ó circunscribir la extensión y generalidad de las acepciones comunes de las palabras" (pág. 123), funciones que no son propias de las oraciones-sustantivo, las cuales son "conjuntos no determinantes" (A puntes, pág. 124).

28 Aunque en ocasiones la expresión del sujeto pueda omitirse por estar claramente sobrentendido: "El Nominativo de una cláusula es muchas veces una palabra expresada en otra cláusula anterior y sobrentendida en la de que se trate. ¿Come Juan? Come" (Apuntes, págs. 20-21). 
después por Julio Cejador ${ }^{20}$, se perpetuó a través de todo el siglo $\mathrm{xx}$ y ha llegado hasta nuestros días como la más útil, satisfactoria y válida, según he tratado de demostrar en el articulo citado en la nota 4 de estas páginas. Muy valioso es también el criterio con que subdivide cada uno de esos tres grupos oracionales, atendiendo a la función que cada oración subordinada desempeña dentro de su periodo ${ }^{30}$. En el caso de las oraciones-sustantivo distingue cinco clases o funciones: la subjetiva - del nominativo-, la objetiva - del acusativo-, la adnominal - del genitivo-, la de complemento indirecto - del dativo- y la de complemento circunstancial - del ablativo ${ }^{31}$. En el caso de las oraciones-adjetivo, distingue entre las especificativas -que denomina determinantes - y las explicativas - que llama incidentales o precisamente explicativas (Apuntes, pág. 89 y sobre todo Arte, págs. 229-244)-, distinción que ya habia establecido con toda claridad en la gramática española Vicente Salvá ${ }^{32}$ y habían reiterado lingüistas posteriores ${ }^{33}$; pero Benot añade una interesante aportación más: la que se refiere a las "oraciones incidentales referentes a frases" en casos como "Le pagó á céntimo por línea, lo cual (o que, o lo que) no fué mucho" (Arte, pág. 245), adición que revela el rigor, el pormenor con que Benot analizaba las construcciones de la lengua española. $\mathrm{Y}$ en el caso de las oraciones-adverbio, por último, distingue un número mayor de subclases de lo que habian establecido los gramáticos anteriores a él. Ya en los Breves apuntes de 1852 [?] enumera cinco clases: de tiempo, de causa, de modo, de fin y de condición (págs. 92 y 151), y en el Arte añade las comparativas (págs. 276-285), a las que dedica especial atención, así como a las condicionantes (Arte, págs. 267-276).

No pasa por alto las oraciones de infinitivo y de gerundio, a las que también dedica amplia y acertada atención (Apuntes, 143-148 y 152-155 respectivamente), y, escrupuloso en las cuestiones de nomenclatura, anota que, en estricta justicia, no son verdaderas oraciones, sino propiamente frases, como todas las expresiones cuyo verbo no está construido en forma personal ${ }^{34}$.

20 Cf. La lengua de Cervantes, vol. I : Gramática, Madrid, 1905.

* Llamo periodo a la expresión formada por dos - a veces, más de dos- oraciones, entre las que se establece una relación sintáctica determinada, ya coordinante, ya subordinante. Por ejemplo "Trabaja mucho pero gana poco" (período adversativo), "O se lo vendes o se lo prestas o se lo regalas" (periodo disyuntivo), "Llora porque tiene hambre" (período causal), " $\mathrm{Si}$ vienes, te lo daré" (periodo condicional), etc. (Cf. el libro citado en la nota 13 , pp. 34-44).

31 Cf. Apuntes, págs. 106-115, y Arte, págs. 286-326.

32 Cf. su Gramática de la lengua castellana, París, 1830. Cito por la $5 .^{a}$ edición, Valencia, 1840 ; cf. págs. 369-370).

3s Con el nombre de "oraciones de relativo", que Benot conoce pero que subordina al de oraciones-adjetivo atendiendo a su función más que a la naturaleza del nexo introductorio (Apuntes, pág. 152).

3 Por lo cual se trata de infinitivos subordinados o dependientes (Apuntes, nota 1 
Una última observación, a manera de breve colofón, sobre la perspicacia de Benot en su análisis de la lengua viva. La referente a un tipo de oraciones que han recibido muy poca atención por parte de los gramáticos, cuando no han sido totalmente ignoradas. $\mathrm{Y}$ es el de ciertas oraciones, formalmente yuxtapuestas, que no mantienen relación sintáctica precisa con las otras oraciones de la cláusula, sino que están como injertadas en ella, por lo que Benot, advirtiendo que son "verdaderamente incidentales", las denomina intercalares o de paréntesis: "Su hermana, ;si aún merece ese nombre!, le ha delatado" o "El último plazo, tenlo presente, se cumple mañana". Oraciones de este tipo se buscarian inútilmente en la mayor parte de las gramáticas de la lengua española. Benot no las pasó por alto.

de la pág. 145), núcleos, pues, de frases, de acuerdo con lo transcrito en la nota 17 de este trabajo. 